\title{
Teaching Biostatistics to Medical Students of the Altai State Medical University
}

\author{
Nina Trukhacheva, Nikolay Pupyrev, Ylia Alyabieva, Svetlana Tschernysheva \\ Altai State Medical University \\ 656038, Russian Federation, Barnaul, Lenin Street, 40 \\ tn10@mail.ru,pnp57@mail.ru, julial1981@list.ru, svetaschka@mail.ru
}

\begin{abstract}
The current research presents some principles and settings in teaching biostatistics. The purpose of study is to enhance the teaching of biostatistics in Russian medical schools and overcome some problems by applying new approaches and innovation techniques. The research included the questionnaire of students, teachers and postgraduates of the Altai State Medical University. There were applied different approaches and studying by means of learning system MOODLE with differentiated courses in biostatistics. Categorical data were analyzed using the chi-square test and a P-value less than 0.05 was considered statistically significant. The findings showed some new approaches and methods in education to improve the biostatistical competence of medical students. The changing in content of biostatistical course would increase students' motivation if it were maximum approximated to the real medical cases. The analysis of the results proved that some approaches are more effective for teaching biostatistics. They allow students to study according to their personal educational goals and paths.
\end{abstract}

Keywords: biostatistics; evidence based medicine; IC technologies; MOODLE; problem-oriented learning.

\section{Introduction}

The knowledge and the skills to use biostatistical technologies are becoming increasingly important in medical science. In the $21^{\text {st }}$ century medical practitioners need to assess new information more than in the past (Viets, 2009).
Only statistics makes it possible to verify and assess the research findings. Therefore, medical students must understand and interpret biostatistics so that they can use its methods when both studying at the university and postgraduate course and when treating patients. Is biostatistics unattractive for medical students and health care providers? - Definitely not 
(Vlassov, 2014). There are doctors and medical students who consider it to be attractive. The bad reputation of biostatistics is related to the fact that statistical technologies are based on mathematical formulas which cause repugnance in most physicians who are not good at Mathematics. But a user does not need to be able to deduce formulas or learn them by heart. It is necessary to understand how statistical technologies should be efficiently used in applied medicine.

How does the future of biostatistics look like?

Biostatistics always plays a tremendous role in clinical medicine and medical research. H. G. Wells believed "Statistical thinking will one day be as necessary for efficient citizenship as the ability to read and write."

The biostatistical competence of medical students is an international problem being actively discussed in different publications (Altman, Bland, 1991), (Bland, 2004), (GrahameSmith, 1995). The role of biostatistics in medical training is recognized in all countries, and the curricula of almost all medical institutions and schools provide students, post graduates and professionals with the opportunity to study biostatistics.

\section{The problems of teaching biostatistics in Russia}

The on-line analysis of biostatistics curricula in Germany, Austria, Switzerland etc. showed the better worldwide image of biostatistical education in medical schools than in Russian ones. This is due to some historical events in our country. During the epoch of Stalin biostatistics was subject to criticism and its development was slowed down (Leonov, 2010). Furthermore, it affected the scientific researches in the educational sphere. There is a significant disagreement in the content of the course of biostatistics in medical curricula.

Some of the most common problems of studying biostatistics in medical schools are listed below:
- the lack of initial statistical knowledge;

- the lack of time allocated for training biostatistics;

- students' attitudes to the subject (they don't like it because it is taught by formal methods of training).

The purpose of the study is to enhance the teaching of biostatistics in Russian medical schools and overcome some problems implementing new approaches and innovative techniques.

\section{Materials and methods}

The research included the survey results of firstyear students (190) and third-year students (123) of the medical faculty of the Altai State Medical University in Barnaul along with graduate students (30) and listeners of post-graduate education (35).

The web-questionnaire on the Moodle platform contained the following questions:

1. Please, specify from where you got the initial knowledge of statistics

2. Please, rate the importance of biostatistics for applied medicine

3. Please, rate the importance of biostatistics for academic medicine

4. Do you prefer to solve applied statistics problems with statistical applications or manually?

5. What statistical applications do you prefer when processing statistical data?

6. Do you approve of the use of interactive and multimedia training programs in studying biostatistics?

7. Do you approve of the use of the MOODLE platform in studying biostatistics?

The workshop on statistical technologies was organized for post-graduate students, and the practical experience and results of different scientific researches on application of statistical methods were analyzed. Numerical data were recorded as frequency/percentage and analyzed 
using the Chi-square test with significance level at 0.05 .

\section{Results and Discussion}

In Russia the basics of mathematical statistics are taught for the first year students during the premedical phase. Pre-medical students are not yet ready to critically evaluate and correctly interpret the results of observations. In addition, they study only the basic concepts of statistics, such as descriptive statistics and confidence intervals. But even elementary concepts of biostatistics are difficult for students to absorb, because there is a lack of prior knowledge of it. Generally, medical students are concentrated on studying medicine and fundamental sciences, so they do not express the great wish to learn biostatistics. Our survey, conducted on biostatistics, showed that formal methods of training (formulas and calculations) neither engage the students to study biostatistics nor make them like the subject. The lectures are boring and are not well-presented thus it is difficult to realize the aim of learning.

First-year students generally do not consider biostatistics important science in clinical practice. Nearly $67.89 \%$ of first-year students do not understand the purpose of studying of biostatistics, $18.95 \%$ consider it important, $13.16 \%$ found it difficult to answer.

$56.04 \%$ of the third year students consider biostatistics as an important subject for clinical medicine, $23.32 \%$ indicate its importance as more likely "yes" than "no". As for the role of biostatistics for scientific researches, opinions of postgraduate students were distributed as follows: "important" - 70.00\%, "no" - 20.00\%, "I don 't know" - 10.00\%.

$20.00 \%$ of respondents gained the statistical knowledge at the secondary school, $73.30 \%$ during studying in the first year at the ASMU and $6.70 \%$ - at the college. The unexpected results of the survey are explained by the fact that the $3^{\text {rd }}$ year students have not made any scientific researches yet and have mastered minimum skills in clinical medicine. Postgraduate students appreciate the study of biostatistics much higher and become aware of its importance for clinical thinking, decision making and data evaluation.

Students indicate insufficient time allocated for the study of biostatistics. It is not enough to learn the most of the important methods such as logistic regression analysis, multidimensional methods, survival analysis, etc.

\section{Pragmatic approach for teaching biostatistics}

Our research presents some principles and settings in teaching biostatistics which may help to overcome some problems and improve the teaching of biostatistics in Russian medical schools. We try to solve each of the following problems by different approaches, supposing, for example, that studying by means of the MOODLE training platform with differentiated courses in biostatistics will improve the biostatistical competence (Trukhacheva, Tchernysheva, Krjklina, 2011). Moreover, we expected that the changing the content of biostatistical course would increase students' motivation, if it is maximum approximated to the real medical cases.

The goal of teaching biostatistics is to eliminate the fear of biostatistics among the medical students. The teacher should show them how relevant the study of the subject is. The course should be aimed at increasing students' motivation towards it. One of the best ways of motivation is to present the publications from medical journals with examples of using and abuse of biostatistics in MOODLE and allow students to criticize them on the forum.

Moreover, the problem-oriented approach should be implemented to stimulate learning and to focus on student's work instead of traditional approach with formal lecture presentations (Lloret, 2009), (Shannon, 1988). Problem-oriented learning makes students to actively participate in their personal studying. Medical students should work with real data instead of examples from the textbooks. It is the best method to motivate the students who take an active position in their selfeducation. They enter the university with different level of competence; some of them are interested in the subject, others are not. 
According to the survey data, biostatistics seems boring for students if traditional teaching approach, that is the one with manual calculations and drawing critical regions, is implemented. Interactive, computer-based approach should be introduced. The use of computers allows the students to focus on the interpretation of the analysis rather than on manual calculations. Nowadays, a lot of biostatistical software are available (SPSS, STATA, STATISTICA, NCSS).

The results of the experiment showed that computer skills assisted to $89.40 \%$ of students learning biostatistics; $93.10 \%$ approved of computer-based approach for solving biostatistical problems. The preferences among software were as follows: Statistica - 63.30\%, Excel - $26.60 \%$, other software - $10.10 \%$. A sizable number of the $3^{\text {rd }}$-year studentspossess adequate and sufficient computer skills and emphasize the advantages of interactive and multimedia tutorials and teaching material.

The comparative analysis of the results of students' tests on biostatistics with the use of the MOODLE training system was carried out by using chi-square-test. Two groups of the first year students were compared. One of them was taught biostatistics with traditional approach and another one with the MOODLE training platform with an interactive biostatistics course. The curriculum and the level of complexity of both courses were the same. The results are presented in Table 1.

\begin{tabular}{|c|c|c|}
\hline $\begin{array}{c}\text { Teaching } \\
\text { approach }\end{array}$ & $\begin{array}{c}\text { All tasks were } \\
\text { made } \\
\text { successfully }\end{array}$ & $\begin{array}{c}\text { Some tasks were } \\
\text { not made }\end{array}$ \\
\hline traditional & 68 & 12 \\
\hline e-learning & 104 & 6 \\
\hline
\end{tabular}

Table 1. The comparative analysis of the results of students' tests on biostatistics

The chi-square statistic is $4.92(p=0.027)$. The chi-square statistic with Yates correction is 3.87 $(p=0.049)$. Therefore, the difference between groups is significant at $p<0.05$.

From the psychological and technical points of view, students are ready to use the MOODLE training platform for learning biostatistics. The presentation of content in MOODLE enhances the students' motivation for learning (Trukhacheva et al., 2010), (Trukhacheva, Tchernysheva, Krjklina, 2011).

Students cannot read and understand medical literature without having special knowledge of biostatistics and research methodology. Altman study (Altman, Bland, 1991) reported that "statistical errors are so common that $50 \%$ of medical literature have statistical flaws". Another research of McGuigan (McGuigan, 1995) informed that "serious statistical errors were found in $40 \%$ of articles published in psychiatry journal and 19\% of articles published in the journal "Obstetrics and Gynecology".

The teacher must inform students about the methodology in designing a research (research design, data collection, sampling etc.) because without proper biostatistical analysis any research article is rejected at the initial review.

Furthermore, teaching of biostatistics should not be limited to the use of data analysis techniques only. It is important that students are able to implement all the statistical methods for the collected data for their interpretation.

The teacher must pay students' attention to the translator's "false friend" to prevent misunderstanding of some statistical terms like association, correlation etc.

\section{Conclusions}

In our opinion, to improve the teaching of biostatistics, the content of the curriculum should be updated every 3 years considering the latest progress and advances in biostatistics and mathematic sciences. A course of biostatistics may be efficient and valuable only if biostatistical notions are being trained, reinforced and applied throughout the whole education period. It may lead to success in training.

Students should be taught applying up-to-date biostatistical technologies; teachers must ensure the sequence and consistency of the subject to avoid contradictions in terminology. The negative attitude to biostatistics can be easily changed by using interactive teaching methods e.g. MOODLE. 
In our research, the role of teachers of clinical departments in advance of methods of evidential medicine and studying of biostatistics for the whole period of training in the institution of higher education is not studied. We consider this direction as prior in future researches.

The analysis of the results proved that MOODLE is an effective learning platform for studying biostatistics. We consider the students to have the right to the information access at any form and the possibility to study according to their personal educational goals and paths. The participants of the experimental project of MOODLE evaluated it as a convenient flexible educational platform, which can be recommended to study biostatistics if all didactic principles are observed. But it should be noted that the methodological work is solid and timeconsuming and requires effort from the administrative link and the faculty of any medical institution.

\section{References}

Altman, D. G., Bland, J. M. (1991). Improving Doctors' Understanding of Statistics. Journal of the Royal Statistical Society. Series A (Statistics in Society), 154(2), 223-67.

Bland, J. M. (2004). Teaching statistics to medical students using problem-based learning: The Australian experience. BMC Medical Education, 4(31), 1469-1472.

Grahame-Smith, D. (1995). Evidence based medicine: Socratic dissent. BMJ, 310, 11261127.

Leonov, V. (2010). Evidence-based or doubtful? Downloaded 23. 10. 2012., from http://biometrica.tomsk.ru/leonov_2006.htm

Lloret, A. (2009). The process of evidence-based medicine. Journal of Feline Medicine and Surgery, 11(7), 529-529.

McGuigan, S. M. (1995). The use of statistics in the British Journal of Psychiatry. British Journal of Psychiatry, 167(5), 683-688.
Shannon, H. S. (1988). Development of a Problem-Based Course in Biostatistics. Proceedings of the American Statistical Association Section on Statistical Education, 220-221.

Trukhacheva, N., Pupyrev, N., Tchernysheva, S., Epryntzeva, L. (2010). E-Learning-Plattform MOODLE für die Medizinausbildung in der Altaier Medizinische Universität (Russland) weitere Aufbau und Perspektiven. Kongressband "Kompetenzen und Kompetenzentwicklung von Hochschullehrer/inne/-n", Brno, 183-190.

Trukhacheva, N., Tchernysheva, S., Krjklina, T. (2011). The Impact of E-learning on Medical Education in Russia. E-Learning and Digital Media, 8(1), 31-35.

Viets E. (2009). Lessons from Evidence-Based Medicine: What Healthcare Designers Can Learn from the Medical Field. HERD: Health Environments Research \& Design Journal, 2(2), 73-87.

Vlassov V. (2014). Is Evidence Based Public Heath in crisis? The European Journal of Public Health, 24(6), 873-873. 